\title{
Cosas de España. Ensayos, artículos y crítica literaria
}

Gerald Brenan y Carlos Pranger (eds.) (2019).

Madrid: Fórcola, 320 páginas.

ISBN 978-84-17425-25-8.

\section{La faz de España}

Gerald Brenan y Carlos Pranger (eds.), con prólogo de Alfredo Taján (2020).

Sevilla; Renacimiento, 352 páginas.

ISBN 978-84-17950-54-5.

(1)

Lucas Margarit

Universidad de Buenos Aires, Argentina

lucasmargarit@gmail.com

La figura de Gerald Brenan tiene un reconocimiento que se enmarca en primer lugar en relación con las letras inglesas de comienzos del siglo XX y su relación con el grupo Bloomsbury, en especial con Lytton Strachey o Leonard y Virginia Woolf; para luego también situarse en el conjunto de la cultura española, ante todo en la comunidad de Andalucía donde residió durante largos períodos. Entre 1919 y 1934 vivió esporádicamente en la aldea de Yegen, en la región de Las Alpujarras, Granada, estableciéndose luego, en 1935, en Churriana, Málaga. Por ser partidario del bando republicano tuvo que huir, vía Gibraltar, de vuelta a Inglaterra y no puede regresar definitivamente a España hasta 1953, cuando vuelve de manera definitiva a Málaga, primero a Churriana, y luego a Alhaurín el Grande, donde muere en 1987. En el medio, durante 1949, hará un viaje por la España meridional de un poco más de dos meses de duración como un observador perspicaz que será el motivo del segundo volumen que comentaremos.

Estamos entonces ante la reivindicación de un autor, de un hispanista que desde una mirada diferente supo comprender el centro de una cultura que no solo fue su objeto de estudio, sino también fue una experiencia de casi toda una vida y nos referimos a la literatura, a sus místicos, a la historia y sus políticas, etc. Instalado en el sur de España pudo comprender desde esa perspectiva las peculiaridades de todo el territorio peninsular.

Y como me refiero a estas dos publicaciones no podemos dejar de lado la presencia y la acción constante por recuperar sus libros de la Casa Gerald Brenan de Churriana, Málaga, gracias a su proyecto Biblioteca Brenan, así como también de su editor y gran conocedor de su obra, Carlos Pranger.
El primer volumen que nos ocupa, Cosas de España, se trata de una recopilación realizada por Pranger de artículos, prólogos o ensayos publicados en su mayoría en inglés en diferentes revistas y libros de ambos lados del Atlántico, desde la revista Horizon -fundada por Cyril Connolly y publicada en Londres desde 1939 a 1950- hasta el New York Times, junto con algunos pocos en español que aparecieron en $E I$ despeñaperros andaluz o en Diario Sur de Málaga más hacia el final de su carrera. Un aspecto que debemos subrayar es la variedad de registros de este volumen, desde ensayos de crítica sobre autores españoles hasta relatos de tono autobiográfico, en ambos casos se refiere Brenan a una experiencia personal con respecto a las obras que comenta y -claro está-con respecto a situaciones de su propia vida.

Entre los textos de crítica literaria, me gustaría destacar los dedicados a la vida de san Juan de la Cruz publicados originariamente en la revista Horizon en 1947, donde la historia de la vida del santo es narrada con una fluidez asombrosa y donde Brenan muestra a un público inglés la necesidad de establecer un nexo entre la vida y la obra del poeta, así como de constituir una mirada que se aparte meramente de lo pintoresco. La segunda parte, dedicada a los poemas de san Juan de la Cruz, tiene en horizonte, la lectura de un público inglés, al explicar los sonidos de los versos o la cadencia de la palabra poética. Estos dos ensayos son sin dudas la antesala de uno de sus trabajos más importantes: St John of the Cross: His Life and Poetry (1973). Asimismo, otro ensayo que nos pareció interesante por su perspectiva fuera del canon academicista se trata de "Cervantes: novelista y filósofo" donde no analiza desde el lugar evidente la novela Don Quijote de la Mancha, sino que establece 
relaciones con el contexto histórico y con otras obras de la tradición española y proyecta de este modo una perspectiva particular que remite a por lo menos un par de aspectos a considerar y que ya hemos comentado: la perspectiva de un inglés y la explicación a un lector no hispano, por lo tanto, en varios aspectos a un lector de lengua española podrán parecerle cercanos pero creo que justamente allí radica lo interesante, volver sobre una obra "propia" desde otro lugar.

Benito Pérez Galdós, Góngora o Federico García Lorca también son autores que forman parte de esta cartografía que nos presenta Pranger en esta compilación y que se extiende por diferentes zonas de la historia literaria, cultural y política de España y que deberíamos tener en cuenta tanto para pensar en los modos de leer de un inglés en España como en nuestra manera de acercarnos a España desde el filtro de Brenan.

Me gustaría destacar también dos aspectos de este libro que creo fundamentales, en primer lugar, la traducción en la que los textos conservan un tono similar al original dándonos la idea de estar leyendo un ensayo que nos coloca en cercanía con el mundo español. Este libro, leído en un invierno en Buenos Aires, trae el paisaje luminoso de la Costa del Sol, pero también se hace vívido lo triste y sus experiencias y referencias a la Guerra Civil y a la dictadura franquista. De allí que me interesa rescatar esta inflexión ensayística que recorre cada uno de los textos aquí presentados conservando la idiosincrasia de cada época y de cada tipo de publicación (revista, libro, periódico). La variedad de temas se debe también al extenso período que recupera esta antología: desde 1925 hasta 1983, casi sesenta años de producción. Pese a ello, la compilación nos muestra una coherencia en temas y en aproximaciones que no desentona con el carácter general de la colección.

El libro se abre con un prólogo "El desafío del laberinto" escrito por su editor, Carlos Pranger, donde nos introduce en la personalidad de Brenan y va reconstruyendo el sendero por el que el autor inglés fue adentrándose en el territorio español. No se detiene solo en aspectos de su vida, sino que se focaliza en aquellos elementos que pueden mostrarnos el perfil de un intelectual que se ha dedicado a comprender una cultura y un estado político diferentes. De allí que en su obra a veces caiga en la comparación con lo que sucede en Inglaterra.

El segundo libro que vamos a comentar, La faz de España [Tha Face of Spain], también está editado por
Carlos Pranger y se trata de la reedición de una traducción de Miguel de Amilibia publicada en 1952 en Buenos Aires por la editorial Losada con el título La faz actual de España. La elección de esta traducción -donde se incorporan cambios y correcciones de erratas - se debe a la necesidad de recuperar una versión más cercana en el tiempo a la original y a funcionar como una especie de homenaje al traductor, exiliado en Argentina y, claro está, en contra de la tiranía que significó el gobierno de Franco en España en el período que nos relata nuestro autor. La edición está acompañada por un prólogo de Alfredo Taján director de Casa Gerald Brenan donde comenta el proyecto de reeditar obras del autor inglés ya olvidadas o difíciles de conseguir hoy en día. Luego nos encontramos con una concienzuda introducción de Carlos Pranger, quien contextualiza el texto de Brenan en el conjunto de su obra, sobre todo en tándem con su otro ensayo El laberinto español, ambas obras prohibidas en la España franquista. Por otra parte, cuenta también algunos aspectos relativos a la vida del viajero y los pormenores de la edición, lo que le permite instalar este libro en la tradición del género de relato de viajes junto a Bruce Chatwin entre otros. Esta edición también cuenta con numerosas notas al pie que explican algunas referencias un poco oscuras para un lector común, o incluso algunas referencias a cuestiones privadas del autor, lo cual es un dato a favor de esta edición con respecto a otras. La edición crítica coloca a La faz de España en un lugar importante para los estudiosos y lectores de la obra de Gerald Brenan.

El libro original se publicó en 1950 en Londres, luego de aquel viaje cuyo recorrido llevaron a cabo Brenan y Gamel Woolsey por el centro y sur de España durante 1949. Si en apariencia puede leerse como un libro de viaje, podríamos considerarlo como una especie de redescubrimiento del mundo español, no solo por parte del autor, que regresaba luego de su huida durante la Guerra Civil, sino donde se produce una especie de anagnórisis y de establecimiento de las bases para lo que sería su estancia definitiva en Andalucía en 1953.

Uno de los aspectos que me parecen centrales de los textos de Brenan es la cercanía con el ámbito de lo popular, lo que coexiste con un conocimiento erudito de la cultura en términos generales y española en particular. Esto le permite acceder a ese limes constante entre lo inmediato y lo mediatizado por la lectura, le permite también comprender ciertos modos de producción de la cultura que recorren todo el paradigma elegido por nuestro autor. El itinerario tiene su inicio en Madrid y se estructura como una especie de 
diario o cuaderno de bitácora donde Brenan va describiendo paisajes y, lo más interesante, va narrando y desplegando el temperamento de cada pueblo, ciudad o territorio que visita. Por estas páginas se entrecruza también la historia con referencias al arte (“El Barroco como arte de propaganda", p. 102) o a la búsqueda de sepulturas o referencias a asesinatos producidos durante la Guerra Civil o la dictadura ( $p$. 16o). Su conocimiento de la cultura española junto con la experiencia de ya haber vivido casi siete años allí le permite a Brenan acercarse de un modo más personal y reflexivo a los asuntos sobre los que le interesa contar alguna experiencia o alguna historia.

Pese a la coexistencia de diferentes registros, el modo en que nos narra cada uno de sus recorridos le permite reproducir la experiencia inmediata, incluso con el uso de ciertos diálogos directos nos permite revivir de modo más pleno el viaje. El hispanista no solo se detiene en exponer su periplo, sino en recuperar parte del paisaje y de las costumbres que también le permitirán reconocer aspectos de la literatura o del perfil de los habitantes de cada terruño. Otro aspecto a comentar es la cotidianeidad que se transparenta en este "diario" de viaje. Brenan nos muestra también cómo se informa frente a los acontecimientos políticos de su tiempo, y expone cómo va uniendo la información para dar un panorama de la situación política de España en ese período. El hecho de ser un testigo permanente, de mostrar información de primera mano no solo hace más verosímil el viaje, sino que también transforma el relato en un documento de época. La edición está acompañada por un mapa que muestra el recorrido y por una serie de fotografías documentales que son de interés ya que nos muestra no solo a los protagonistas del viaje, sino también una España detenida en el momento de los acontecimientos.

Estos dos libros, con fecha de publicación tan cercana —un año separa uno de otro-nos inducen a considerar un proyecto a largo plazo que permita recuperar la figura de Brenan para nuevos lectores y acercar a los antiguos un nuevo perfil de este hispanista inglés a partir de estas nuevas ediciones. 